\title{
High Temperature Capacitive Pressure Sensor Employing a SiC Based Ring Oscillator
}

\author{
Roger D. Meredith ${ }^{1,}$, Philip G. Neudeck, b , George E. Ponchak ${ }^{1, c}$, Glenn M. Beheim ${ }^{1, d}$, \\ Maximilian C. Scardelletti ${ }^{1, \mathrm{e}}$, Jennifer L. Jordan ${ }^{1, \mathrm{f}}$, Liang-Yu Chen, ${ }^{2, g}$, David J. Spry, ${ }^{1, \mathrm{~h}}$ \\ Michael J. Krasowski ${ }^{1, i}$ and Gary W. Hunter ${ }^{1, j}$ \\ ${ }^{1}$ NASA Glenn Research Center (GRC), 21000 Brookpark Road, MS 77-1, Cleveland, OH 44135, USA \\ ${ }^{2}$ OAI / NASA GRC, 21000 Brookpark Road, MS 77-1, Cleveland, OH 44135, USA \\ a roger.d.meredith@nasa.gov, ${ }^{b}$ neudeck@nasa.gov, 'george.e.ponchak@nasa.gov, 'glenn.m.beheim@nasa.gov,

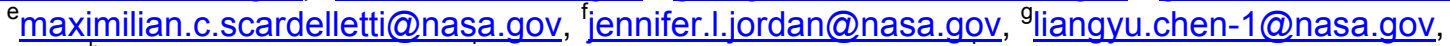 \\ havid.j.spry@nasa.gov, 'michael.j.krasowski@nasa.gov, ${ }^{\mathrm{j}}$ gary.w.hunter@nasa.gov
}

Keywords: SiC-based ring oscillator, high temperature circuits, capacitive pressure sensor

\begin{abstract}
In an effort to develop harsh environment electronic and sensor technologies for aircraft engine safety and monitoring, we have used capacitive-based pressure sensors to shift the frequency of a SiCelectronics-based oscillator to produce a pressure-indicating signal that can be readily transmitted, e.g. wirelessly, to a receiver located in a more benign environment. Our efforts target $500{ }^{\circ} \mathrm{C}$, a temperature well above normal operating conditions of commercial circuits but within areas of interest in aerospace engines, deep mining applications and for future missions to the Venus atmosphere. This paper reports for the first time a ring oscillator circuit integrated with a capacitive pressure sensor, both operating at $500{ }^{\circ} \mathrm{C}$. This demonstration represents a significant step towards a wireless pressure sensor that can operate at $500{ }^{\circ} \mathrm{C}$ and confirms the viability of $500{ }^{\circ} \mathrm{C}$ electronic sensor systems.
\end{abstract}

\section{Introduction}

For future aerospace/aircraft propulsion systems to meet the requirements of decreased maintenance inspections, improved performance, and increased safety, the inclusion of intelligence into the propulsion system design and operation is necessary [1]-[3]. This implies the development of sensor systems able to operate at temperatures through $500{ }^{\circ} \mathrm{C}$ and higher to complement conditions present in an engine. Likewise, Venus exploration missions require systems that can operate in the harsh environments present on the Venus planetary surface, which has an average surface temperature of $462{ }^{\circ} \mathrm{C}$ [4]. In addition, high temperature sensors are finding uses in commercial applications, such as in automobile on-engine sensors that operate up to $150^{\circ} \mathrm{C}$, power brake sensors that operate through $140{ }^{\circ} \mathrm{C}$, and engine exhaust sensors operating through $850^{\circ} \mathrm{C}$ [5]. Furthermore, monitoring of the subterranean temperature for geothermal energy requires sensors operating to as high as $300{ }^{\circ} \mathrm{C}[6]$, and oil and natural gas drilling requires sensors and electronics that operate through $225^{\circ} \mathrm{C}$ [7].

In this paper, we demonstrate for the first time the integration of a capacitive pressure sensor with a SiC ring oscillator circuit that operates at $500{ }^{\circ} \mathrm{C}$. This represents a significant step towards the goal of integrating sensors, electronics, wireless circuits and power into a single high-temperature capable system. Section II describes the ring oscillator, Section III describes the capacitive pressure sensor, Section IV presents the measured results, and Section V provides concluding remarks. 


\section{Ring Oscillator Circuit}

A schematic diagram of the ring oscillator integrated with the capacitive pressure sensor is shown in Figure 1a. The capacitive pressure sensor (described in the next section) is connected between one of the nodes of the three-stage ring oscillator and ground potential. The building block of this ring oscillator is the $\mathrm{SiC}$ integrated circuit NOR gate, shown in more detail in Figure 1b [8]. Pressure applied to the diaphragm results in a change in the capacitive coupling between the oscillator and ground, which shifts the oscillation frequency. Figure 2a shows the SiC JFET logic-gate packages [9] assembled in a single block (approximately $3-\mathrm{cm}$ cube) with insulated gold wires welded to the extruded pins. Stacking the packages shortens the connections between the components and improves the frequency response of the oscillator by reducing parasitic reactance. In this circuit demonstration, the two inputs of each NOR gate were externally connected to produce an inverter. The oscillator and capacitive pressure sensor are shown together inside the test furnace in Figure $2 \mathrm{~b}$.

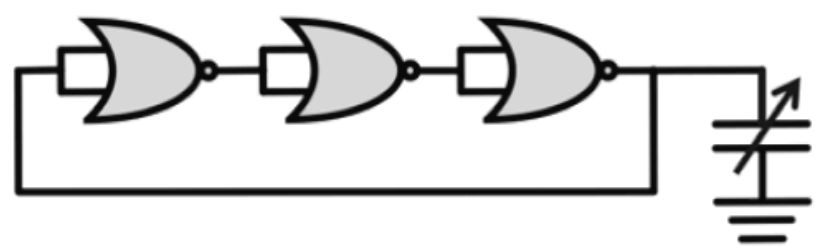

Figure 1a (above): Schematic diagram of the ring oscillator circuit showing integration of the capacitive pressure sensor.

Fig. 1b (right): Detailed schematic of each 6H-SiC JFET NOR logic gate from Figure 1a.
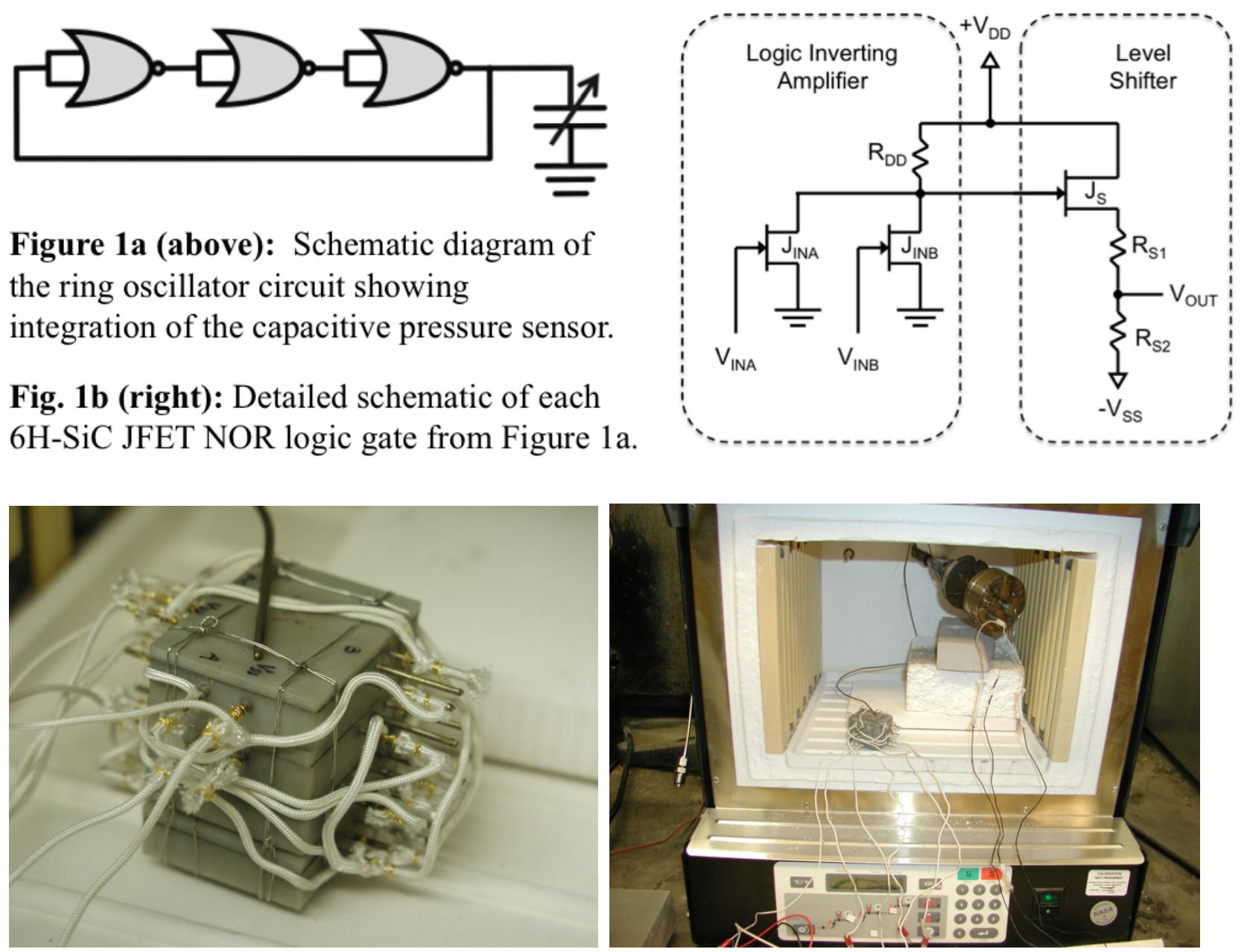

Figures 2a (left), 2b (right): Figure 2a is a close up view of the stack of SiC JFET logic gate packages connected as a three-stage ring oscillator. Figure $2 \mathrm{~b}$ shows the test setup inside the $23-\mathrm{cm}$ wide box furnace with the ring oscillator adjacent to the capacitive pressure sensor.

\section{Capacitive Pressure Sensor}

A capacitive pressure sensor component from a MKS Instruments, Inc. Baratron ${ }^{\mathrm{TM}}$ vacuum gauge (which can be baked out at $300^{\circ} \mathrm{C}$ ) was disassembled, modified and reassembled to produce a 
differential pressure sensor which can withstand $500^{\circ} \mathrm{C}$. Inside the sensor, an electrode (a metal film on a ceramic disc) faces the 4-cm diameter Inconel ${ }^{\mathrm{TM}}$ diaphragm. Capacitance measurements were taken between these conductive surfaces. Connections to the metal film were made with nickel wire and routed outside the sensor and furnace. A wire was attached to the case of the sensor to make contact with the Inconel diaphragm. The spacing between the outer edge of the diaphragm and the ceramic disc was set using a circumferential spacer to accommodate the application of several psi of pressure before the diaphragm contacted the ceramic disc. The opposite side of the capacitive pressure sensor diaphragm was adapted to $1 / 4$ inch stainless steel tubing and nitrogen was supplied to pressurize the sensor.

Initial characterization of the pressure sensor was performed at room temperature. A Keithley $590 \mathrm{CV}$ Analyzer was used to measure the capacitance between the electrode on the ceramic disc and the sensor housing. With no pressure applied to the diaphragm, the capacitance was about $20 \mathrm{pF}$, and at a pressure of $3 \mathrm{psig}$, the capacitance increased to $270 \mathrm{pF}$. At pressures higher than $3 \mathrm{psig}$, the electrodes came into contact.

\section{Testing of Sensor with Ring Oscillator}

The oscillator circuit and pressure sensor were tested inside a commercial box furnace, as shown in Figure $2 \mathrm{~b}$, at room temperature and $500{ }^{\circ} \mathrm{C}$. Thermocouples were mounted on the pressure sensor and oscillator circuit to ensure that they both were at least $500{ }^{\circ} \mathrm{C}$ during the heated test. To facilitate independent testing of the sensor and circuit, connections between the two were made outside the furnace. The lengths of wires shown in Figure $2 b$ contributed significant stray reactance; shorter leads would be preferred, and, eventually, a custom built integrated circuit, closely coupled to a MEMS-based sensor, should be employed to produce a compact and robust smart sensor.

To connect the sensor with the ring oscillator, one of the nodes of the ring oscillator was connected to the center electrode on the ceramic disc, while the circuit ground was connected to the sensor case and diaphragm. The signal frequency of the ring oscillator residing inside the furnace was measured remotely (more than 1 meter away from the furnace) using a digitizing oscilloscope operated in spectrum analyzer mode. In particular, the $10 \mathrm{M} \Omega$ oscilloscope probe was attached to the $+\mathrm{V}_{\mathrm{DD}}$ wire where it connected to the front of the $\mathrm{V}_{\mathrm{DD}} \mathrm{DC}$ power supply. Thus sensor data is transmitted via the power supply wires only, without need for any separate (additional) data wires. At $500{ }^{\circ} \mathrm{C}$, the spectra shown in Figure $3 \mathrm{a}$ were observed, for pressures of 0 and 3 psig. Figure $3 \mathrm{~b}$ shows how the peak frequency shifts as a function of applied pressure, over the range from 0 to 3 psig, at $500{ }^{\circ} \mathrm{C}$.

\section{Concluding Remarks}

While considerably more development is required to realize a fully wireless $500{ }^{\circ} \mathrm{C}$ sensor system, this work demonstrates a feasible approach to this goal. Work is underway to fabricate $500{ }^{\circ} \mathrm{C}$ MEMS-based capacitive pressure sensors which can be closely coupled to SiC integrated-circuit (single chip) ring oscillators, also under development, to provide a much higher oscillation frequency suitable

for wireless transmission. This work confirms that a ring oscillator approach is well suited to encoding pressure changes as frequency shifts which are readily transmitted via wireless and other means (such as on the power line, as demonstrated here). 

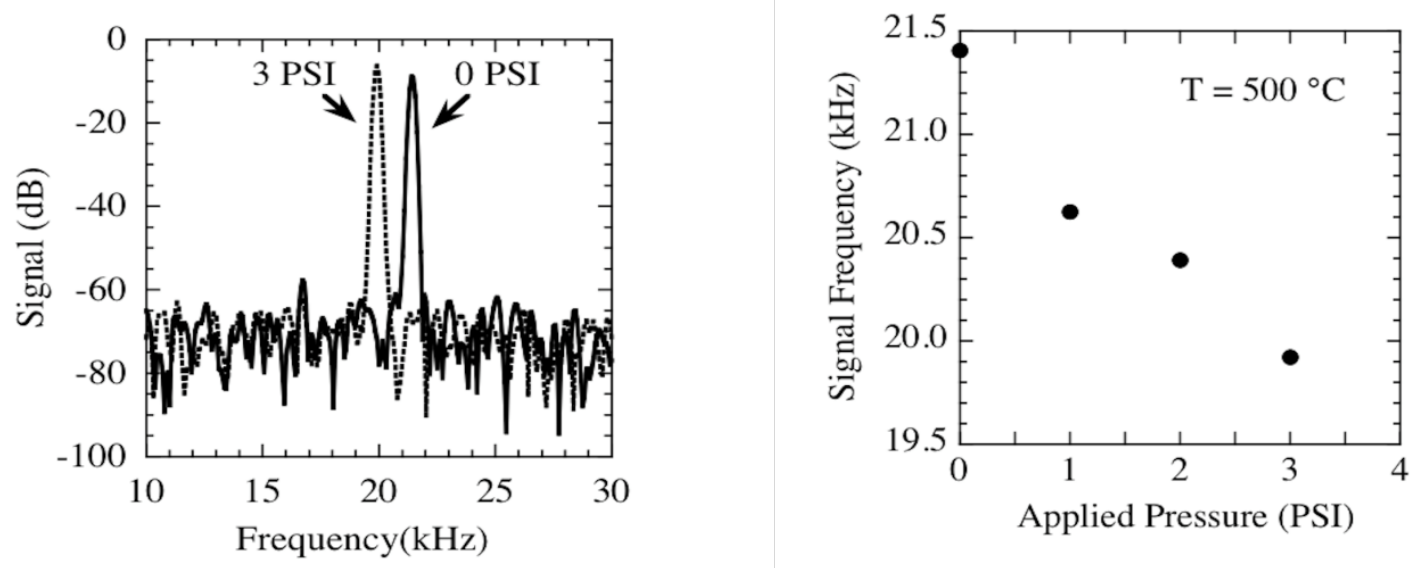

Figures 3a (left), 3b (right): Figure 3a illustrates the change in observed oscillator frequency responding to pressure applied to the capacitive pressure sensor at $500{ }^{\circ} \mathrm{C}$. Figure $3 \mathrm{~b}$ shows the coupled frequency shift as a function of applied pressure at $500{ }^{\circ} \mathrm{C}$.

\section{References:}

[1] J. S. Litt, D. L. Simon, S. Garg, Ten-Heui Guo, C. Mercer, R. Millar, A. Behbahani, A. Bajwa, and D. T. Jensen, "A survey of intelligent control and health management technologies for aircraft propulsion systems," NASA/TM-2005-213622, ARL-TR-3413, May 2005.

[2] A. R. Behbahani, "Need for robust sensors for inherently fail-safe gas turbine engine controls, monitoring, and prognostics," AFRL-PR-WP-TP-2007-217, Nov. 2006, also in Proc. 2006 52nd Int. Instrumentation Symp.

[3] G.W. Hunter, et al., "Intelligent Sensor Systems for Integrated System Health Management in Exploration Applications," in System Health Management: with Aerospace Applications, S.B. Johnson, et al., ed., John Wiley \& sons LTD, pp. 405-419 (2011).

[4] Final Report of the Venus Science and Technology Definition Team, Venus Flagship Mission Study, NASA, Jet Propulsion Laboratory, April 17, 2009.

[5] R. W. Johnson, J. L. Evans, P. Jacobsen. J. R. Thompson and M. Christopher, "The changing automotive environment: high-temperature electronics," IEEE Trans. Electronics Packaging Manufacturing, Vol. 27, No. 3, pp. 164-176, July 2004.

[6] B. A. Goldstein, A. J. Hill, A. Long, A. R. Budd, F. Holgate, and M. Malavazos, "Hot rock geothermal energy plays in Australia," in Proc. Thirty-Fourth Workshop on Geothermal Reservoir Engineering, Stanford Univ., Stanford, CA, Feb. 9-11, 2009.

[7] R. A. Normann, "First high-temperature electronics products survey 2005," Sandia National Laboratories Sandia Report SAND2006-1580, April 2006.

[8] P. G. Neudeck, L.-Y. Chen, M. J. Krasowski, and N. F. Prokop, "Characterization of 6H-SiC JFET Integrated Circuits Over A Broad Temperature Range from $-150 \mathrm{C}$ to $+500 \mathrm{C}$," in Materials Science Forum, vol. 645-648, Silicon Carbide and Related Materials 2009, A. J. Bauer, P. Friedrichs, M. Krieger, G. Pensl, R. Rupp, and T. Seyller, Eds. Switzerland: Trans Tech Publications, 2010, pp. 1135-1138.

[9] SiC logic gates packages assembled by Sienna Technologies Inc., http://www.siennatech.com/.

\section{Acknowledgements:}

Work was carried out by the NASA Glenn Research Center with the assistance of Greg Blank, Chris Conrad, Terry Ferrier and Jim Mazor. This work was supported by the VSST (Vehicle Systems Safety Technologies) Project of the NASA Aviation Safety Program. 